\title{
No changes in the number of vasoactive intestinal polypeptide (VIP)-expressing neurons in the suprachiasmatic nucleus of homosexual men; comparison with vasopressin-expressing neurons
}

\author{
J.-N. Zhou a,b,* , M.A. Hofman ${ }^{\text {a }}$, D.F. Swaab ${ }^{\text {a }}$ \\ ${ }^{a}$ Graduate School Neurosciences Amsterdam, Netherlands Institute for Brain Research, Meibergdreef 33, 1105 AZ Amsterdam, The Netherlands \\ ${ }^{b}$ Ningxia Medical College, Yinchuan, Ningxia, People's Repuplic of China
}

Accepted 6 December 1994

\begin{abstract}
In an earlier study we found more than twice as many vasopressin (AVP) neurons in the suprachiasmatic nucleus (SCN) of homosexual men as compared to heterosexual men. The present measurements in the same individuals showed that there is no difference in the number of vasoactive intestinal polypeptide (VIP)-expressing neurons in the SCN. The reduced nuclear diameter of both VIP and AVP neurons in the SCN as found in homosexual men points to metabolic alterations in the SCN in relation to sexual orientation.
\end{abstract}

Keywords: Vasoactive intestinal polypeptide; Vasopressin; Human hypothalamus; Suprachiasmatic nucleus; Sexual orientation; Homosexuality

The suprachiasmatic nucleus ( $\mathrm{SCN}$ ) is the principle pacemaker of the circadian timing system $[8,9,11]$. In addition, it is involved in regulating reproductive processes $[2,12,15,19,21]$. Recently it was found that male rats treated neonatally with an aromatase inhibitor show a clear sexual preference behavior for the female partner in the late dark phase. When tested early in the dark phase they had a lesser preference for the female, or no partner preference at all [1]. This suggests that the SCN may also be involved in the control of sexual orientation.

In an earlier study we found that the population of vasopressin (AVP)-expressing neurons in the SCN of homosexual men is 1.7 times larger in volume and contains 2.1 times as many cells as in heterosexual men. The present study was undertaken to investigate whether there are also changes in one of the other main subpopulations of peptidergic SCN cells, i.e. vasoactive intestinal polypeptide (VIP) neurons, in relation to sexual orientation.

The brains of 10 homosexual males who had died from AIDS were compared with a reference group

" Corresponding author at address "a". Fax: (31) (20) 696-1006. consisting of the brains of 13 presumed heterosexual male subjects that did not show primary neurological or psychiatric diseases (Table 1). (For individual pathological clinical and histological data see Swaab and Hofman [16].) A comparison was made with the data obtained earlier on AVP neurons in the SCN of the same subjects and with the VIP data of individuals in the same age range [21].

The hypothalamic sections were immunocytochemically stained according to the method described by Swaab and Hofman [16], using anti-VIP (Viper, $18 / 9 / 86)$ as the first antibody. This was raised in our institute following conjugation to thyroglobulin by means of glutaraldehyde [3]. Antibodies against glutaraldehyde-thyroglobulin present in the polyclonal antiserum caused background staining and were removed by adsorption with thyroglobulin Sepharose beads, treated with glutaraldehyde [10].

The morphometric procedures used to determine the number of VIP-expressing neurons have been described before $[14,16]$. The total number of VIP-expressing cells in the SCN was computed by multiplying the numerical VIP cell density, as determined by the deconvolution technique, with the volume of the VIP cell population in the SCN. The Mann-Whitney U-test 
Table 1

Pathological and morphometric parameters of the brain material, and VIP and AVP subpopulations in the human suprachiasmatic nucleus (mean \pm S.E.M.)

\begin{tabular}{|c|c|c|}
\hline & Control males & Homosexual males \\
\hline Age (years) & $34 \pm 2$ & \pm 2 \\
\hline Brain weight (g) & $1441 \pm 29$ & 1393 \\
\hline Postmortem (h) & $32 \pm 8$ & $21 \pm 5$ \\
\hline Fixation (days) & $37 \pm 3$ & $35 \pm 7$ \\
\hline \multicolumn{3}{|c|}{ Cell number $\left(\times 10^{3}\right)$} \\
\hline AVP population it & $7.75 \pm 1.16$ & $14.16 \pm 1.80^{*}$ \\
\hline VIP population & $2.29 \pm 0.31$ & $2.32 \pm 0.33$ \\
\hline \multicolumn{3}{|c|}{ Cell population iolume $\left(\mathrm{mm}^{3}\right)$} \\
\hline AVP population "a & $0.28 \pm 0.03$ & $0.44 \pm 0.05^{\circ}$ \\
\hline VIP population & $0.04 \pm 0.01$ & $0.05 \pm 0.01$ \\
\hline \multicolumn{3}{|c|}{ Cell density $\left(\times 10^{3} / \mathrm{mm}^{3}\right)$} \\
\hline AVP population " & $27.17 \pm 3.17$ & $32.64 \pm 3.44$ \\
\hline VIP population & $69.60 \pm 8.74$ & $49.87 \pm 4.47$ \\
\hline \multicolumn{3}{|c|}{ Rostro-caudal axis ( $\mathrm{mm})$} \\
\hline AVP population " & $1.37 \pm 0.13$ & $2.25 \pm 0.28$ \\
\hline VIP population & $1.02 \pm 0.13$ & $1.36 \pm 0.27$ \\
\hline \multicolumn{3}{|c|}{ Maximal cross-sectional area $\left(\mathrm{mm}^{2}\right)$} \\
\hline AVP population “ & $0.59 \pm 0.09$ & $0.60 \pm 0.10$ \\
\hline VIP population & $0.11 \pm 0.03$ & $0.08 \pm 0.01$ \\
\hline \multicolumn{3}{|c|}{ Nuclear diameter $(\mu \mathrm{m})$} \\
\hline AVP population " & $5.73 \pm 0.15$ & $5.23 \pm 0.13$ \\
\hline VIP population & $6.55 \pm 0.13$ & $5.60 \pm 0.15^{\circ}$ \\
\hline
\end{tabular}

VIP = vasoactive intestinal polypeptide; $A V P=$ vasopressin.

"Data from Swab and Hofman [16].

$P<0.03 ; \cdots P<0.01$ compared to control group.

was used to look for significant differences between subjects groups, and $P<0.05$ was considered to be significant.

Brain weight, postmortem delay and duration of fixation did not differ between the reference group and homosexual group (Table 1) and there was no signifi- cant correlation with any of the morphological parameters studied $(P>0.12)$. VIP-expressing neurons in the SCN were mainly present in the ventrolateral and centromedial part of the SCN, while the AVP-expressing neuron population was mainly located in the dorsal and centromedial portion of the SCN (Fig. 1), which is agreement with previous reports $[7,9,13]$. The volume of the subpopulation of the VIP-expressing neurons and the VIP cell number of the SCN were not significantly different in the reference and homosexual group ( $P>0.1$ and $P>0.2$, respectively, Table 1). Nor were any significant differences found in the density, rostro-caudal axis or maximal cross-sectional area of the subpopulation of VIP neurons in the SCN (Table 1). The only significant difference regarding the VIP neuron population was that the mean nuclear diameter of VIP neurons in the SCN was smaller in homosexual males than in heterosexual males (Table 1).

In the present study no difference was found in the number of VIP neurons in the SCN between the reference and homosexual group. The volume of the VIP cell population in the SCN was not different either. This is in contrast to the enlarged AVP cell population in the SCN of homosexual men [16], which has been hypothesized to be due to a different interaction of sex hormones and brain development $[15,16,17]$. This idea was reinforced by recent observations showing that perinatal administration of an aromatase inhibitor induces an increase in the number of AVP-expressing SCN neurons in rat [19]. It is, however, not known at present whether a similar relationship exists between sex hormones and the development of VIP neurons in the human SCN.

An interesting finding of the present study is the significantly smaller VIP cell nuclear diameter in the homosexual males compared to the reference group. Comparison with other data obtained by our group [21]

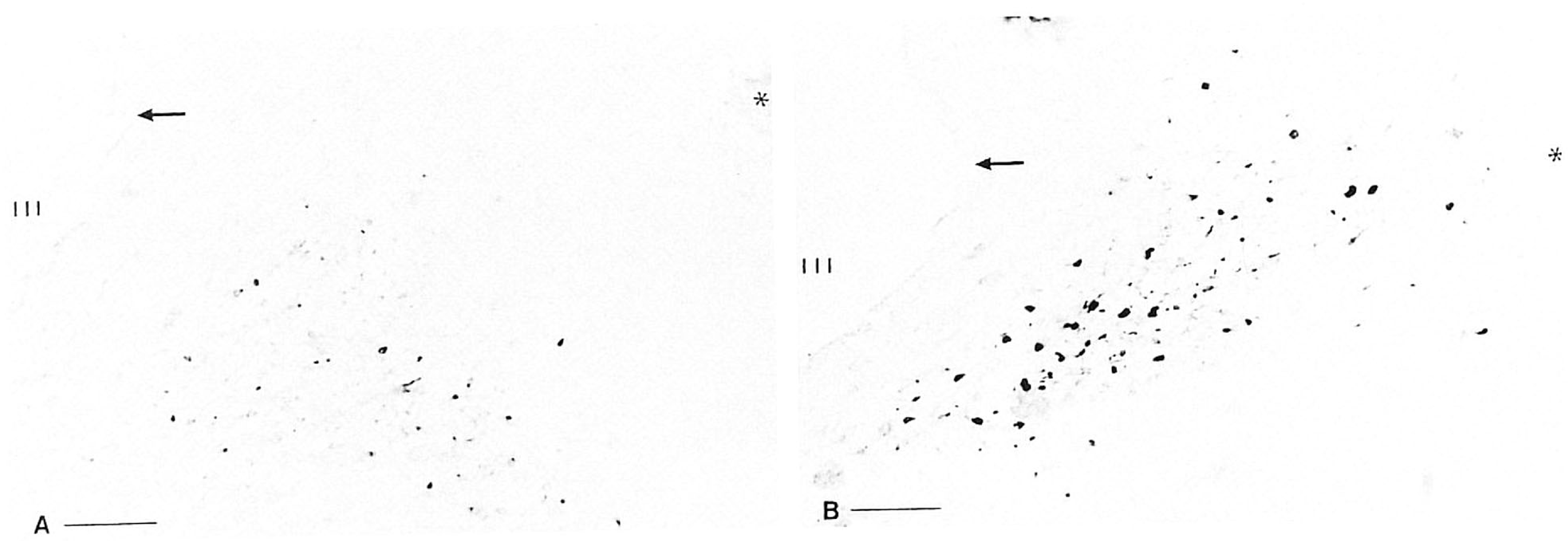

Fig. 1. Vasoactive intestinal polypeptide (VIP) and vasopressin (AVP)-expressing neurons in frontal sections (6 $\mu \mathrm{m}$ ) of the human suprachiasmatic nucleus (SCN). The arrow points to the same spot in the wall of the third ventricle (III) and the asterisk shows the same blood vessel in both sections. A: VIP neurons located at the ventrolateral part of the SCN (Patient No. 86262 Section No. 744\#). B: the adjacent section (745\#) shows that AVP neurons are distributed mainly at the dorsal and centromedial part of the SCN. Bars $=100 \mu \mathrm{m}$. 
A VIP cell in the suprachiasmatic nucleus

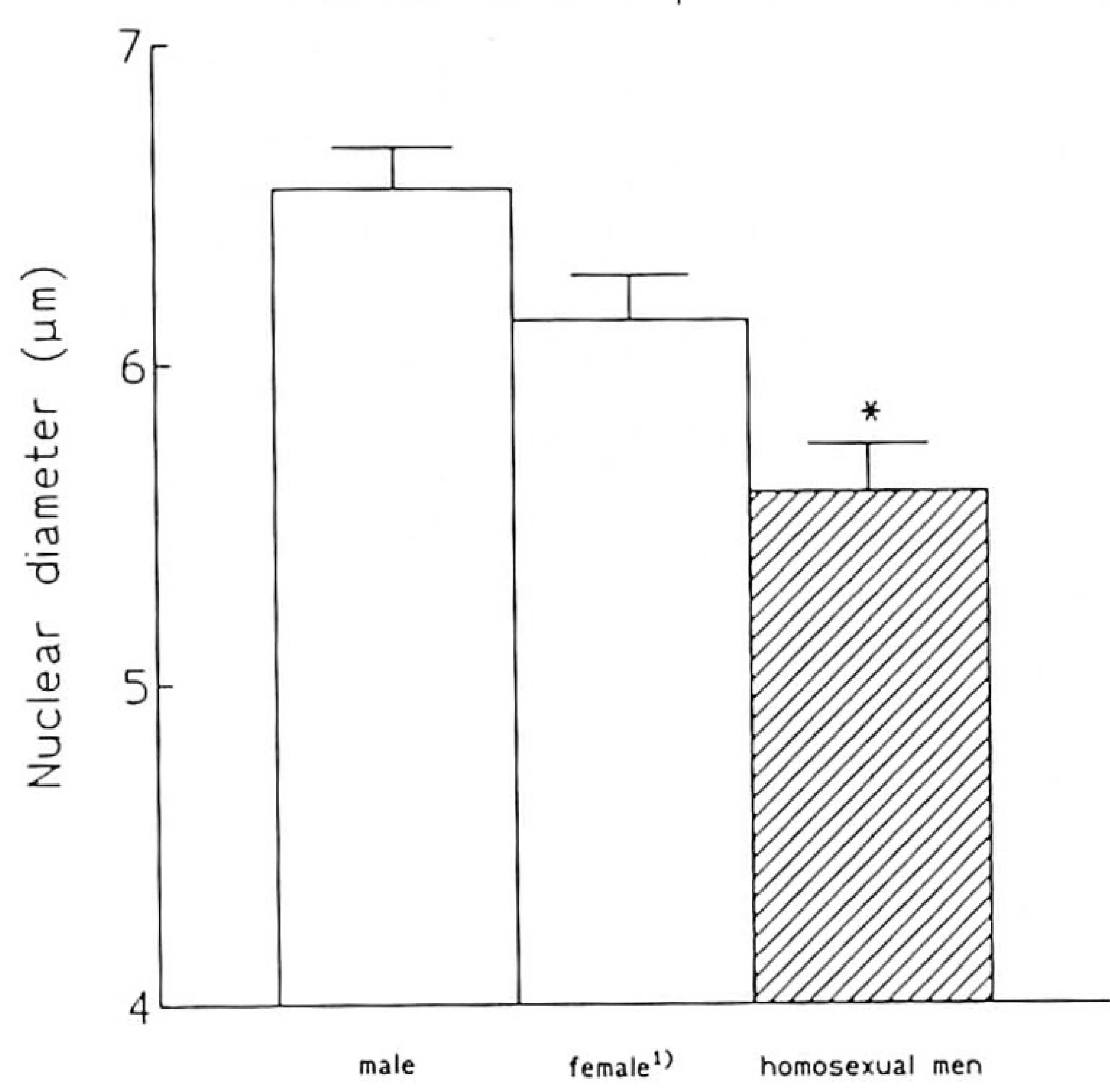

$B$

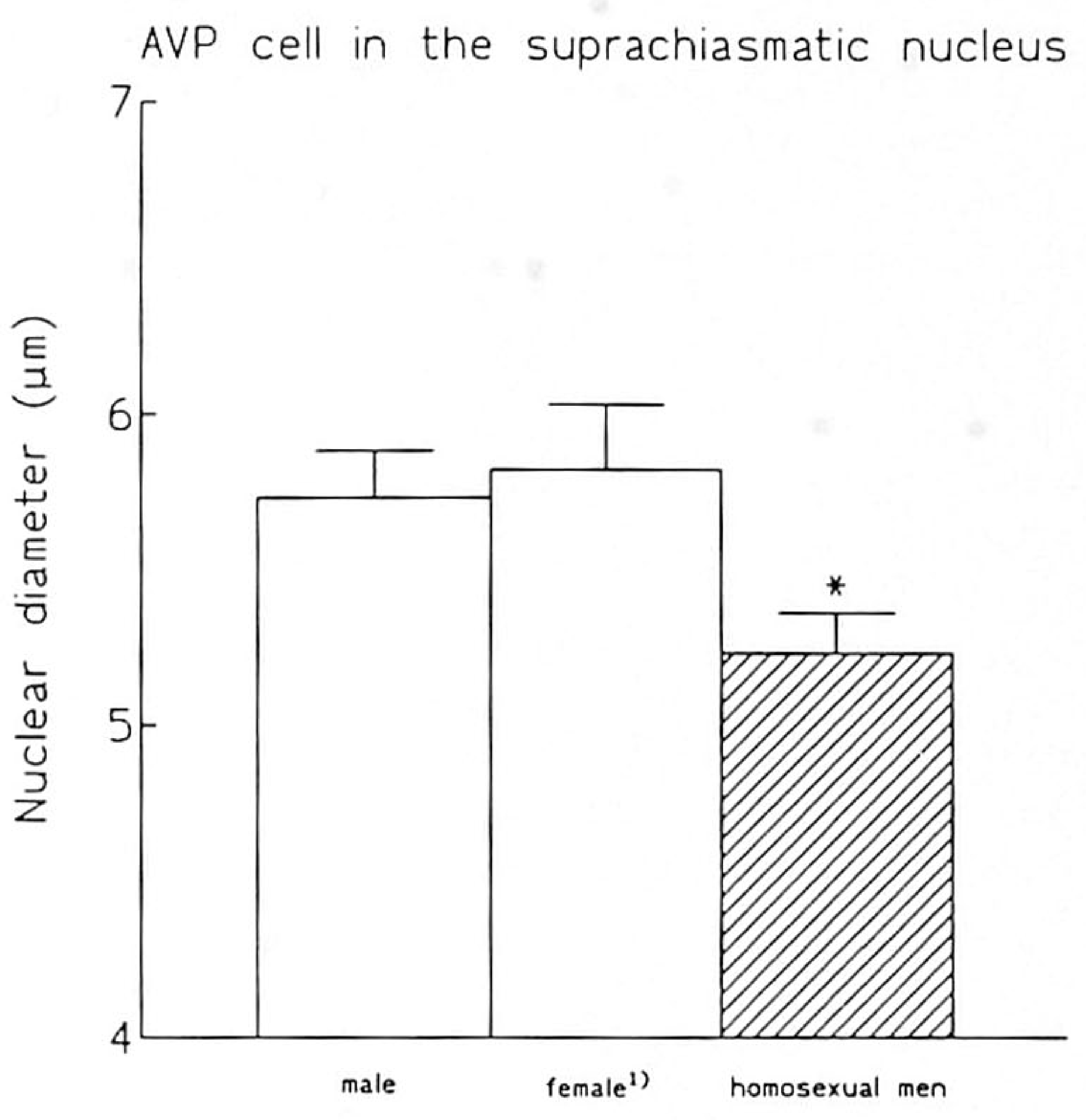

Fig. 2. Mean nuclear diameter of the vasoactive intestinal polypeptide (VIP) and vasopressin (AVP)-expressing neurons in the human suprachiasmatic nucleus (SCN). A.. ' $P<0.02$ compared with reference males and reference females. ' Data from Zhou et al. [21]. B: $P<0.02$ compared with reference males and females. AVP data of reference males and homosexual men from Swaab and Hofman [16]. 'AVP data of reference females from Swaab et al. $[14,18]$.

showed that the nuclear diameter of VIP neurons is also smaller in homosexual men than in heterosexual females (Fig. 2A; $P<0.02$ ). A similar decrease was found in the AVP neurons in the SCN of homosexual men [16] (Fig. 2B). One might presume that the decreased nuclear size to be due to AIDS. However, this does not appear to be the case since the present study also shows that heterosexuals who died from AIDS do not have a decreased nuclear size of AVP-expressing SCN neurons. The mean nuclear diameter of AVP neurons in male heterosexual AIDS patients is $6.02 \pm$ $0.21 \mu \mathrm{m}$ compared with $5.23 \pm 0.13 \mu \mathrm{m}(P<0.01)$ for homosexual men who died from AIDS. The VIP and AVP cell nuclear diameters in the human SCN are, moreover, very stable under many circumstances. They are not affected by aging, Alzheimer's disease, sex $[6,14,18,20,21]$, or the hour or month of death $[4,5]$.

In conclusion, no difference was observed in the number of VIP cells in the SCN of homosexual men, indicating preferential increase in the number of AVP neurons in the SCN observed earlier [16]. The decreased nuclear size of both VIP and AVP neurons points to metabolic alterations in the SCN in relation to sexual orientation. This possibility should be studied further by means of other parameters for SCN neuron activity, such as in situ hybridization of mRNA.

The authors are indebted to NUFFIC for their financial support (J.-N.Z.), to Mr. B. Fisser for his technical assistance, Mr. G. van der Meulen for making the photographs and Ms. O. Pach for her secretarial help. Brain material was obtained from the Netherlands Brain Bank (coordinator Dr. R. Ravid).
[1] Bakker, J., Van Ophemert, J. and Slob, K., Organization of partner preference and sexual behavior and its nocturnal rhythmicity in male rats, Behav. Neurosci., 107 (1993) 1-10.

[2] Brown-Grant, K. and Raisman, G., Abnormalities in reproductive function associated with the destruction of the suprachiasmatic nuclei in females rats, Proc. R. Soc. Lond. B, 198 (1977) 279-296.

[3] Buijs, R.M., Pool, C.W., Van Heerikhuize, J.J., Sluiter, A.A., Van der Sluis, P.J., Ramkema, M., Van der Woude, T.P. and Van der Beek, E.M., Antibodies to small transmitter molecules and peptides: production and application of antibodies to dopamine, serotonin, GABA, vasopressin, vasoactive intestinal peptide, neuropeptide $\mathrm{Y}$, somatostatin and substance $\mathrm{P}$, Biomed. Res., 10 (1989) 213-221.

[4] Hofman, M.A. and Swaab, D.E., Diurnal and seasonal rhythms of neuronal activity in the suprachiasmatic nucleus of humans, J. Biol. Rhythms, 8 (1993) 283-295.

[5] Hofman, M.A., Purba, J.S. and Swaab, D.F., Annual variations in the vasopressin neuron population of the human suprachiasmatic nucleus, Neuroscience, 53 (1993) 1103-1112.

[6] Hofman, M.A., Fliers, E., Goudsmit, E. and Swaab, D.F., Morphometric analysis of the suprachiasmatic and paraventricular nuclei in the human brain: sex differences and age-dependent changes. J. Anat., 160 (1988) 127-143.

[7] Mai, J.K., Kedziora, O., Teckhaus, L. and Sofroniew, M.V., Evidence for subdivisions in the human suprachiasmatic nucleus, J. Comp. Neurol., 305 (1991) 508-525.

[8] Meijer, J.H. and Rietveld, W.J., Neurophysiology of the suprachiasmatic circadian pacemaker in rodents, Physiol. Rev., 69 (1989) 671-707.

[9] Moore, R.Y., The organization of the human circadian rhythm. In D.F. Swaab, M.A. Hofman, M. Mirmiran, R. Ravid and F.W. Van Leeuwen (Eds.), The Human Hypothalamus in Health and Disease. Prog. Brain Res., Vol. 93, Elsevier, Amsterdam, 1992, pp. 101-117.

[10] Pool, C.W., Madlener, S., Diegenbach, P.C., Sluiter, A.A. and Van der Sluis, P., Quantification of antiserum reactivity in immunocytochemistry. Two new methods for measuring peroxidase activity on antigen-coupled beads incubated according to 
an immmunocytoperoxidase method, J. Histochem. Cytochem., 32 (1984) 921-928.

[11] Rusak, B. and Zucker, 1., Neural regulation of circadian rhythms, Physiol. Ret., 59 (1979) 449-526.

[12] Södersten, P., Hansen, S. and Srebro, B., Suprachiasmatic lesions disrupt the daily rhythmicity in the sexual behavior of normal male rats and of male rats treated neonatally with antioestrogen, J. Endocrinol., 88 (1981) 123-130.

[13] Stopa, E.G., King, J.C., Lydic, R. and Schoene, W.C., Human brain contains vasopressin and vasoactive intestinal polypeptide neuronal subpopulations in the suprachiasmatic region. Brain Res., 297 (1984) 159-163.

[14] Swaab, D.F., Fliers, E. and Partiman, T.S., The suprachiasmatic nucleus of the human brain in relation to sex, age and senile dementia, Brain Res., 342 (1985) 37-44.

[15] Swaab, D.F., Gooren, L.J.G. and Hofman, M.A., The human hypothalamus in relation to gender and sexual orientation. In D.F. Swaab, M.A. Hofman, M. Mirmiran, R. Ravid and F.W. Van Leeuwen (Eds.), The Human Hypothalamus in Health and Disease. Progr. Brain Res., Vol. 93. Elsevier, Amsterdam, 1992, pp. $205-219$.

[16] Swaab, D.F. and Hofman, M.A., An enlarged suprachiasmatic nucleus in homosexual men, Brain Res., 537 (1990) 141-148.
[17] Swaab, D.F., Hofman, M.A. and Honnebier, M.B., Development of vasopressin neurons in the human suprachiasmatic nucleus in relation to birth, Dev. Brain Res., 52 (1990) 289-293.

[18] Swaab, D.F., Roozendaal, B., Ravid, R., Velis, D.N., Gooren, L. and Williams, R.S., Suprachiasmatic nucleus in aging, Alzheimer's disease, transsexuality and Prader-Willi syndrome. In E.R. de Kloet, V.M. Wiegant and D. de Wied (Eds.), Neuropeptides and Brain Function, Progr. Brain Res., Vol. 72, Elsevier, Amsterdam, 1987, pp. 301-311.

[19] Swaab, D.F., Slob, A.K., Houtsmuller, E.J., Brand, T. and Zhou, J.N., Increased number of vasopressin neurons in the suprachiasmatic nucleus (SCN) of 'bisexual' adult male rats following perinattal treament with the aromatase blocker ATD, Dev. Brain Res., in press.

[20] Swaab, D.F., Zhou, J.N., Ehlhart, T. and Hofman, M.A., Development of vasoactive intestinal polypeptide neurons in the human suprachiasmatic nucleus in relation to birth and sex, Dev. Brain Res. 79 (1994) 249-259.

[21] Zhou, J.N., Hofman, M.A. and Swaab, D.F., Vasoactive intestinal polypeptide neurons in the human suprachiasmatic nucleus in relation to sex, age and Alzheimer's disease, Neurobiol. Aging, in press. 